\title{
DIAGNOSIS OF THE CONDITION OF COMPONENTS OF SI ENGINE USING WEAR PARTICLES MONITORING
}

Yogesh Sharma ${ }^{1}$ and R B Sharma ${ }^{2}$

\begin{abstract}
The wear is a very common phenomenon during the running condition of components of SI engine. The development and progression of the wear in engine components may create catastrophic failures. In this study, the wear condition in the engine parts has been predicted with colour identification of wear particles from lubricating oil. The experimental set up has been developed and the experiments were conducted with lubrication oil extracted from engine at different running condition. The results demonstrate that the colour identification techniqueof wear particleswhich arise from the different parts of SI engine in lubrication oil correlate well with the severity of wear condition of engine parts.
\end{abstract}

Keywords: Engine, wear, wear debris analysis, engine components, condition monitoring.

\section{INTRODUCTION}

The performance of an SI engine depends upon the health of its components such as piston, cylinder, cylinder head, crankshaft, cam shaft, connecting rod etc. These engine components are manufactured from the different materials. Wear particles may be arise from various sources like friction, corrosion, wear of the engine components during operation [1]. These wear debris can be collected from the lubrication oil and provides the very useful information regarding the condition of engine components. The main aim of this study is the condition monitoring of the SI engine components through the colour identification of wear particles in lubrication oil. The lubrication oil was altered after different kilometres of the vehicle. The wear debris were collected from engine oil and analyzed through developed experimental setup. This technique provides the information about the condition of engine components. The replacement or maintenance of the engine components may be decided upon the basis of this information/ results. It is very helpful for the control of the maintenance cost of engine as well as engine life.

\footnotetext{
${ }^{1}$ Assistant Professor, Department of Automobile Engineering, RJIT, BSF Academy, Tekanpur, Gwalior, M.P.,India

${ }^{2}$ Assistant Professor, Department of Automobile Engineering, RJIT, BSF Academy, Tekanpur, Gwalior, M.P., India
} 
SI engines are mostly used in automotive sector.SI engines suffer from severalproblems[2].These problems are generated due to improper combustion, oil burning, and friction between two parts of engine. Wear debris analysis technique is extensively used in monitoring the condition of a SI engine, machine and gear box. Oil monitoring techniques were used by many researchers like, ferrography technique [3], grey system theory [4, 5], FTIR [6], Rotary Particle Depositor (RPD), Particle Quantifier (PQ) and Spectrometric oil analysis. Ferrography is used to quantify the amount of wear particle within a given oil sample and to conduct microscopic analysis of that debris in order to identify its size, shape and colors of engine parts. [7].

\section{II.EXPERIMENTAL INVESTIGATION}

\subsection{Experimental Setup}

Ferrography is a powerful technique used for oil analysis. It involves separating out solid particles from a lubricant and examining them under a microscope checking characteristic like particle size, concentration, composition, morphology and surface condition of the ferrous and non-ferrous wear particles.

In the developed setup, 12-volt dc motor is used which is driven by $12 \mathrm{~V}$ lead acid battery.Developed experimental setup consists of three chambers, first one is called asmagnetic chamber, second one is called as non-magnetic chamber and thirdone is called as sump chamber. Magnetic chamber is made by a circular magnet which collects the ferrous particle of lubrication oil and then after oil is fed into the second chamber which collects and separates the non ferrous particles of oil and then fed the oil into sump chamber which collects the filtered engine oil. The experimental setup is shown in Fig.1.

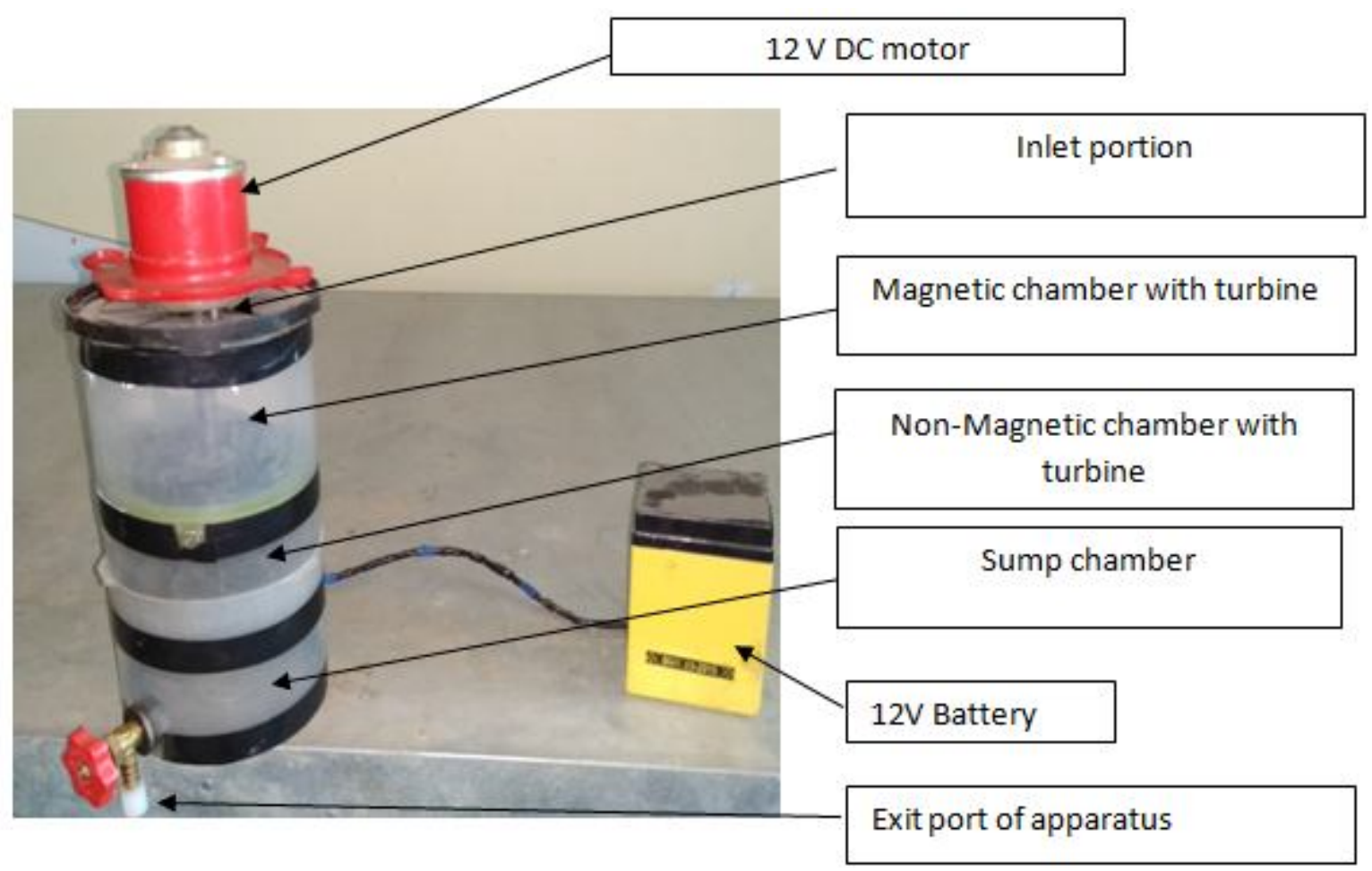

Fig.1. Experimental setup 


\subsection{Experimental procedure}

In this study, the four engine oil samples of Maruti swift LXI (O) are collected at different running condition of vehicle as shown in Table 1 . The experiments are performed on developed experimental setup.

The 4 flasks are collected and cleaned properly. Then after, the engine oil samples labels are placed on the 4 flasks. The labels are 1 st engine oil $(40000 \mathrm{Km}), 2$ nd engine oil $(50000 \mathrm{Km}), 3 \mathrm{rd}$ engine oil $(60000 \mathrm{Km})$, and 4th engine oil $(70000 \mathrm{Km})$. The oil samples are poured into the labeled flask. As the engine oil is poured from the flask into developed experimental seup, it reaches the magnetic chamber. The ferrous particles get separated from the oil and rest of the oil enters the turbine chamber where the oil is rotated through turbine and nonferrous particles are get filtered through strainer. Then the oil is allowed to pass to sump where filtered oil is obtained. Then after, the magnet is disassembled from the magnet chamber and the ferrous particles on the magnet are collected and nonferrous particles are collected from the filter chamber. After collection of wear particles, the particles are washed out by using water and separated on the basis of color identification for each sample. The color of different wear debris particles are correlated with the material of components of SI engine as shown in Table1. The different materials of components of SI engine are mentioned in Table 2.

Table 1: Details of samples of lubrication oil

\begin{tabular}{|l|l|l|}
\hline Sample code & $\begin{array}{l}\text { Vehicle running condition } \\
(\mathrm{Km})\end{array}$ & $\begin{array}{l}\text { Wear debris material } \\
(\% \text { of weight })\end{array}$ \\
\hline 1 & 40000 & $\begin{array}{l}\text { Steel(8\%), Chromium (5\%), } \\
\text { Aluminum (82\%), rest (5\%) }\end{array}$ \\
\hline 2 & 50000 & $\begin{array}{l}\text { Steel (7\%), Aluminum (86\%), } \\
\text { Chromium (3\%), rest (4\%) }\end{array}$ \\
\hline 3 & 60000 & $\begin{array}{l}\text { Steel (3\%), Aluminum (88\%), } \\
\text { Chromium (3\%), Titanium (2\%), } \\
\text { Molybdenum (1\%), rest (3\%) }\end{array}$ \\
\hline 4 & 70000 & $\begin{array}{l}\text { Steel (3\%), Aluminum (90\%), } \\
\text { Chromium (2\%), Molybdenum } \\
(2 \%), \text { Titanium (2\%), rest (1\%) }\end{array}$ \\
\hline
\end{tabular}

Table 2: Various material of components of SI engine

\begin{tabular}{|l|l|l|}
\hline Group No. & Material (Metal) & Components of SI engine \\
\hline 1 & Iron/Steel (Fe) & gear, cam shaft, crankshaft \\
\hline 2 & Chromium $(\mathrm{Cr})$ & $\begin{array}{l}\text { cylinder liner, ring, coating of anti- } \\
\text { friction bearing }\end{array}$ \\
\hline 3 & Copper & anti-friction bearing \\
\hline 4 & Aluminum alloy & piston, piston head \\
\hline 5 & Molybdenum (Mo) & piston ring \\
\hline 6 & Titanium (Ti) & springs, valves \\
\hline
\end{tabular}




\section{RESULTS AND DISCUSSION}

The results demonstrate that the wear debris of steel, aluminum, chromium, titanium, and molybdenum exist in the samples of lubrication oil. The variation of percentage of weight of wear debris ofsteel, aluminum, chromium, titanium, and molybdenum with vehicle running condition has been shown in Fig. 2, Fig.3, Fig.4, Fig.5, and Fig.6 respectively. It is clear from the results; the wear debris of aluminum is more in every sample of lubrication oil. It can be noted from group no. 4 of Table 2, that the piston and piston head are having the aluminum material. Hence, it is clear that there is probability of presence of any fault or deterioration or wear in the components of SI engine which exist in the group no. 4 as shown in Table 2.

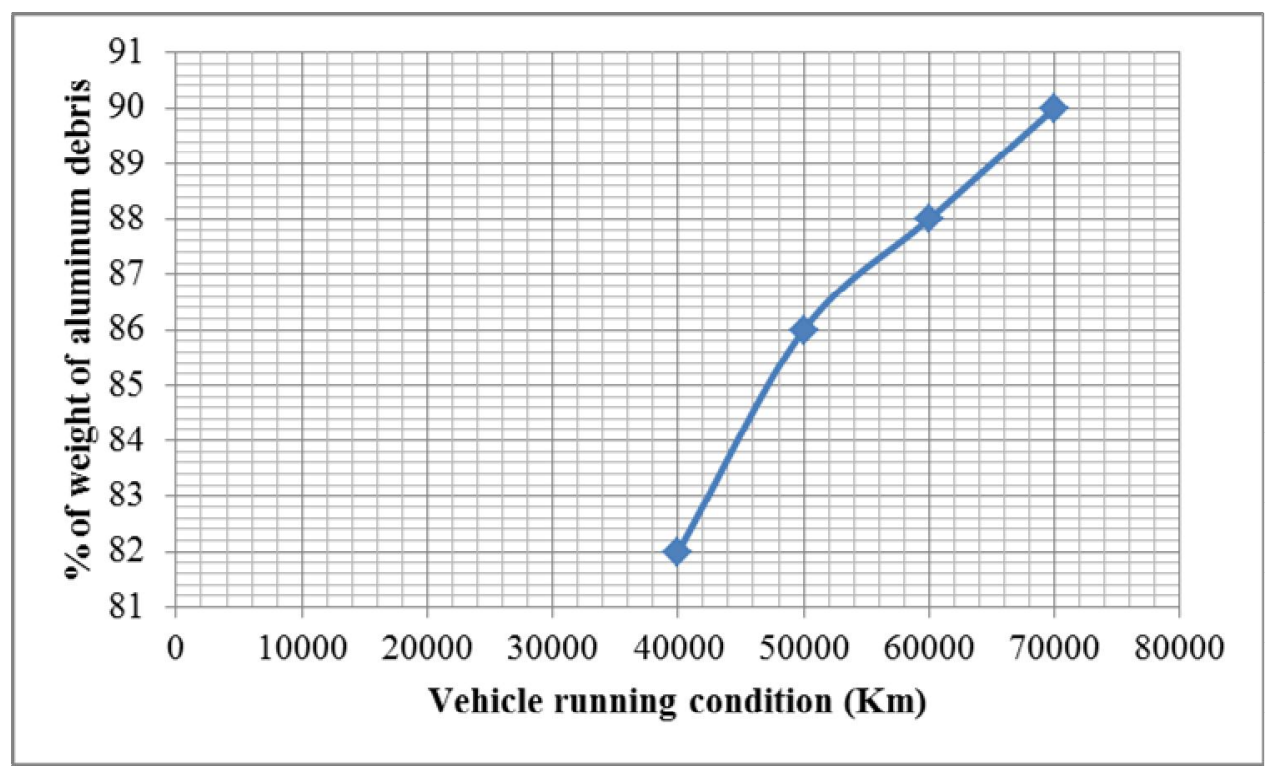

Fig.2. Wear debris of aluminum with vehicle running condition

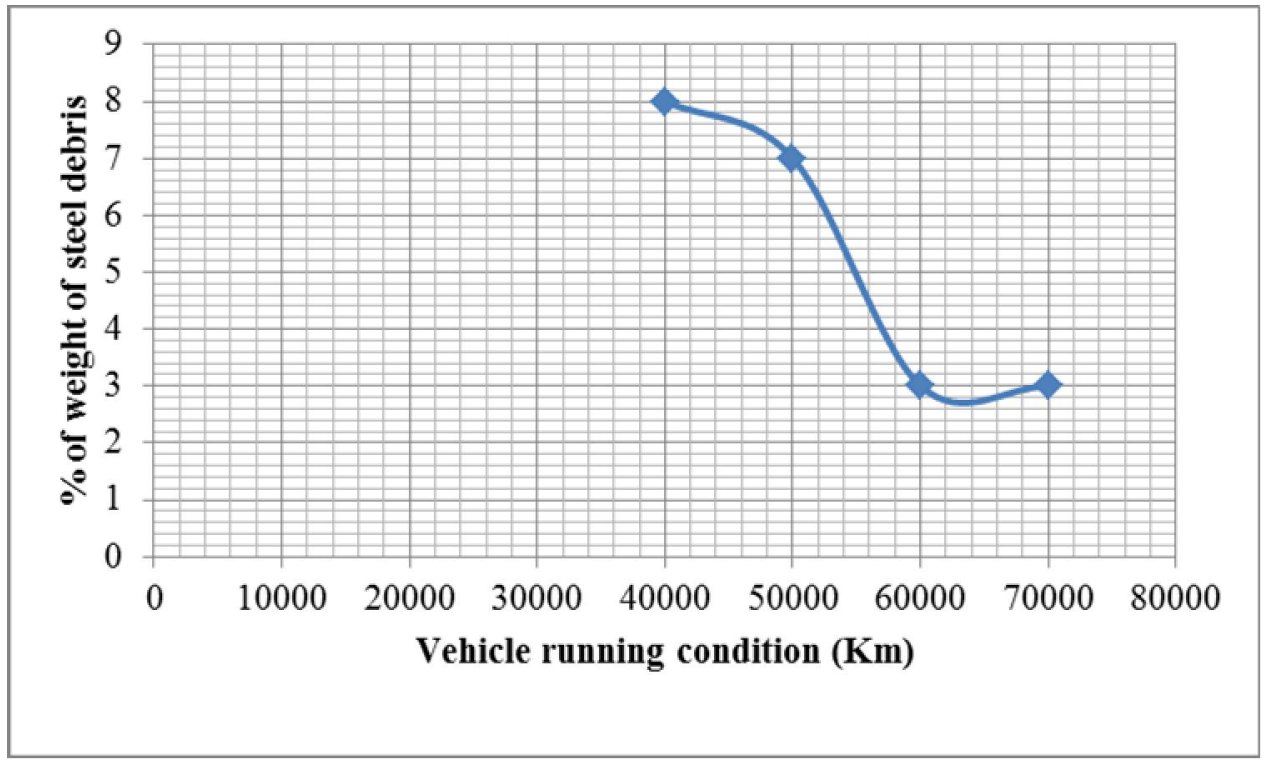

Fig.3.Wear debris of steelwith vehicle running condition 


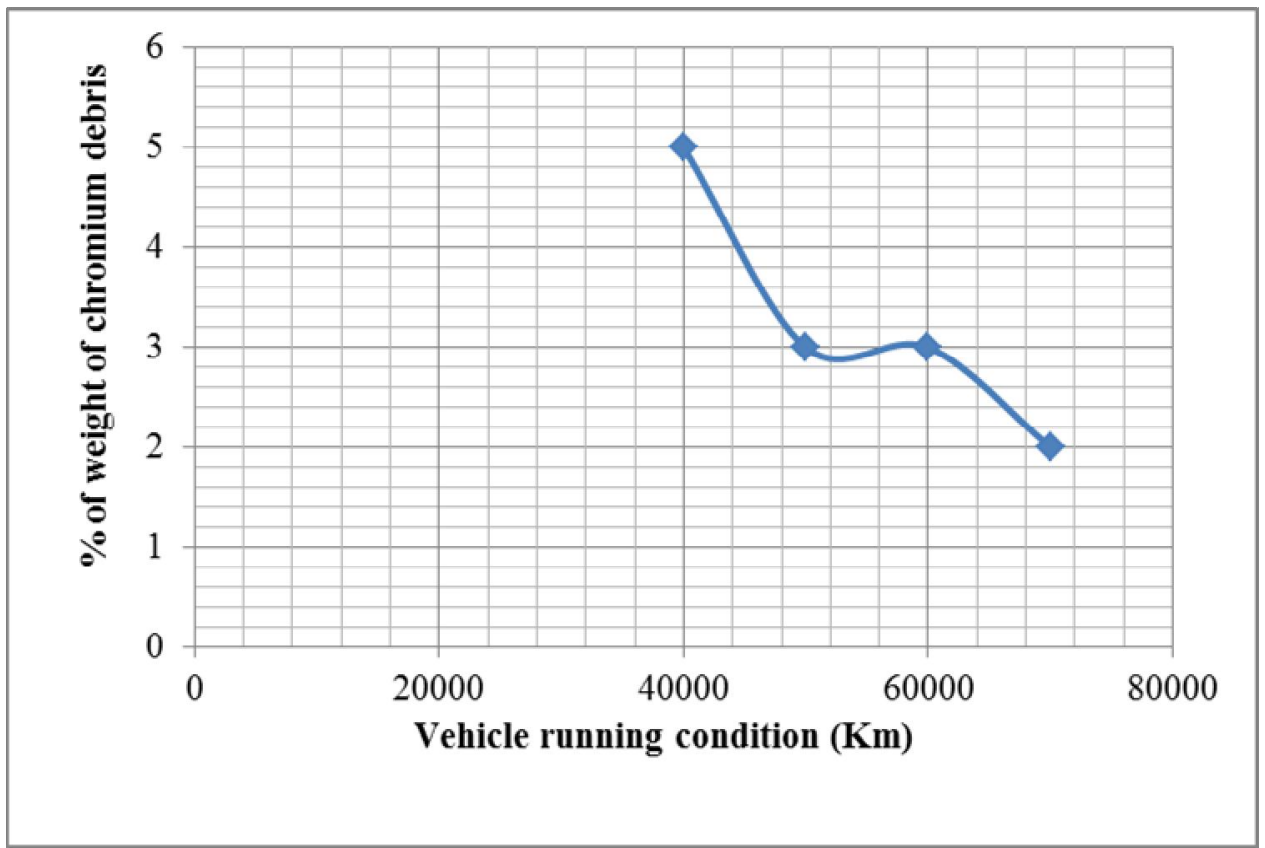

Fig.4. Wear debris of chromiumwith vehicle running condition

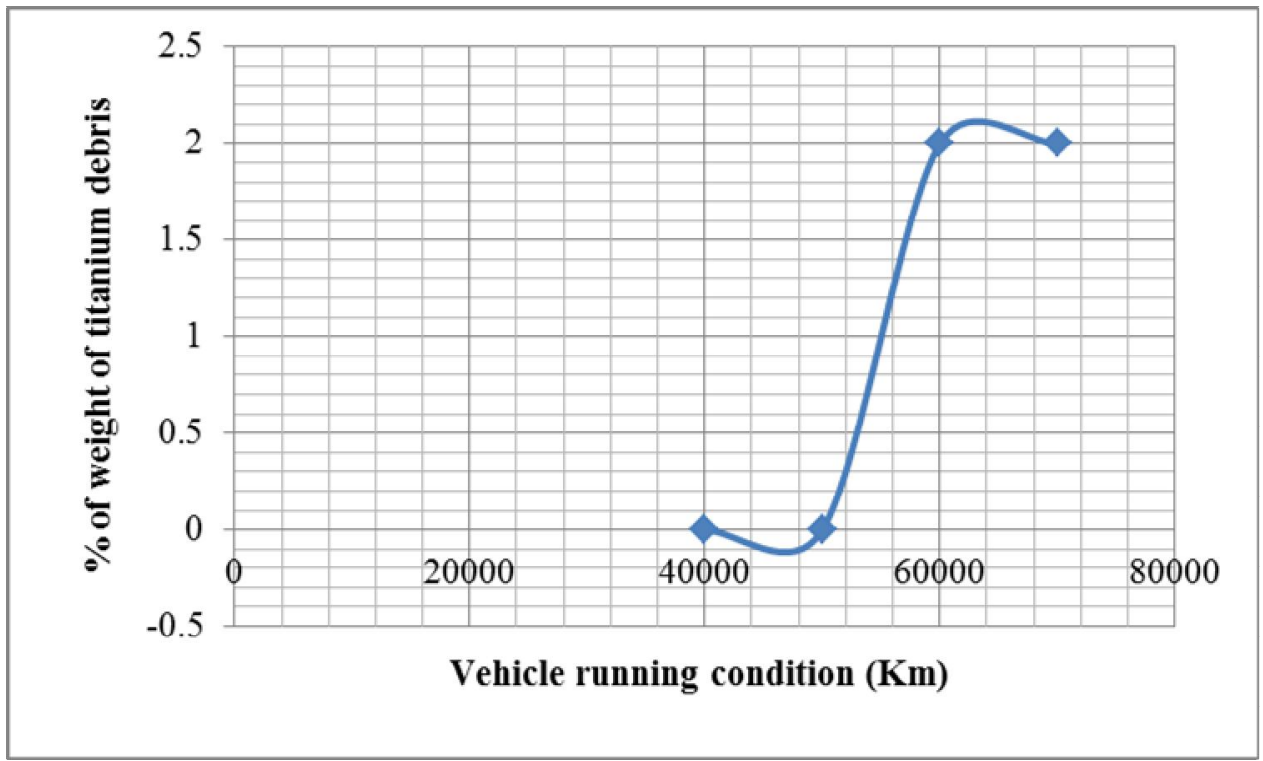

Fig.5. Wear debris of titanium with vehicle running condition 


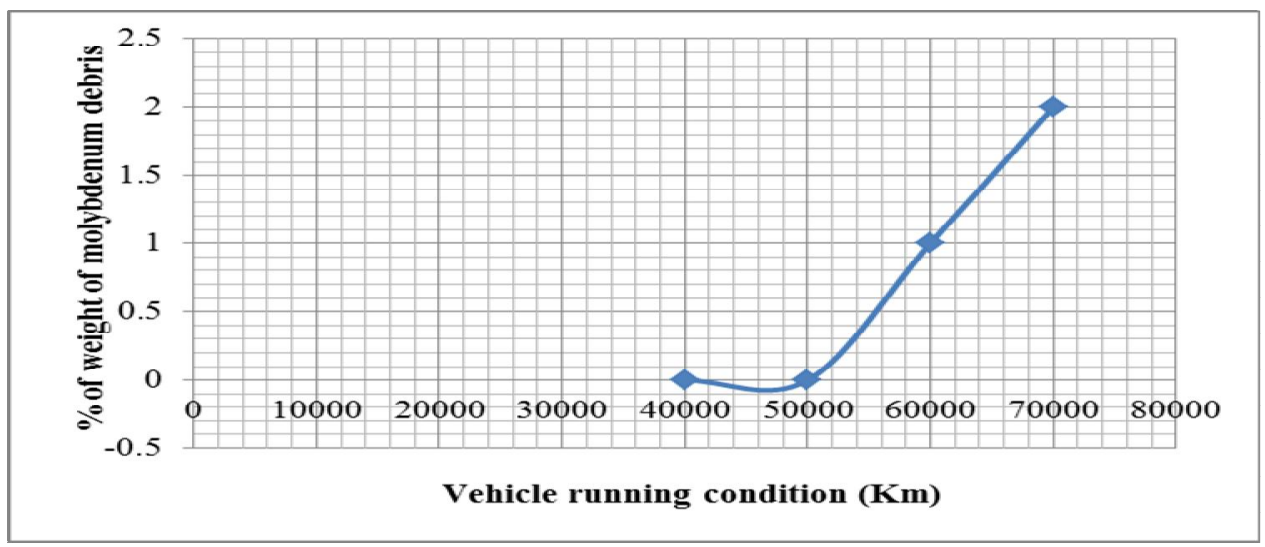

Fig.6. Wear debris of molybdenum with vehicle running condition

\section{CONCLUSION}

The condition of components of SI engine is monitored through wear debris analysis technique. The experimental investigation is presented on the developed experimental setup. The different experiments are performed with various engine oils which are collected at different vehicle running condition. The different components of SI engine have been separated according to their material. It is found that the wear debris of aluminum is more in every sample of lubrication oil. Hence, it is concluded that there is probability of presence of any fault or deterioration or wear in the piston and piston head.

\section{REFERENCES}

[1]. Tonghai Wu, Junqun Wang, Yeping Peng, and YaliZhang, "Description of wear debris from on-line ferrography images by their statistical color", Tribology Transactions, 55: 606-614, 2012.

[2]. Shrawan Kumar Singh, Avinash Kumar Agarwal, Mukesh Sharma, "Experimental investigations of heavy metal addition in lubricating oil and soot deposition in an EGR operated engine", Applied Thermal Engineering , 26, 259-266, 2006.

[3]. Sam George, Santhosh Balla, MridulGautam, "Effect of diesel soot contaminated oil on engine wear", Wear, 262, 1113-1122, 2007.

[4].Xu M, Sha M, Qi M, "Ferrography and spectrum data process of TBMoil”, Journal of Tongji University, 29:1429-33, 2001.

[5].B. J. Roylance, "Ferrography-then and now", Tribology International, 38,857-62, 2005.

[6].J. Wang, X. Wang, "A wear particle identification method by combining principal component analysis and grey relational analysis", Wear,304, 96-102, 2013.

[7].S. Chen, Z. Li, Q. Xu, "Grey target theory based equipment condition monitoring and wear mode recognition, Wear, 260, 438-49, 2006.

[8].G.W. Stachowiak, P. Podsiadlo, "Characterization and classification of wear particles and surfaces", Wear,249, 194-200, 2001.

[9].M. J. Adams, M. J. Romeo, P. Rawson, "FTIR analysis and monitoring ofsynthetic aviation engine oils",Talanta,73, 629-34,2007. 